\title{
Male bilateral risk-reducing mastectomy: Report of a case
}

\author{
Francesca Combi MD ${ }^{1,2}$ (D) | Elisabetta Razzaboni $\mathrm{MS}^{3}$ | Angela Toss MD ${ }^{4,5}$ | \\ Anna Gambini MD² | Simona Papi MD ${ }^{2}$ | Laura Cortesi MD ${ }^{4}$ | Giovanni Tazzioli MD²,5
}

\author{
${ }^{1} \mathrm{PhD}$ Clinical and Experimental Medicine, University of Modena and Reggio Emilia, Modena, Italy \\ ${ }^{2}$ Division of Breast Surgical Oncology, Department of Medical and Surgical, Maternal-Infantile and Adult Sciences, University Hospital of Modena, Modena, \\ Italy \\ ${ }^{3}$ Hospital Psychology Service, University Hospital of Modena, Modena, Italy \\ ${ }^{4}$ Division of Oncology, Department of Medical and Surgical, Maternal-Infantile and Adult Sciences, University of Modena and Reggio Emilia, Modena, Italy \\ ${ }^{5}$ University of Modena and Reggio Emilia, Modena, Italy
}

Correspondence: Francesca Combi, Division of Breast Surgical Oncology, Department of Medical and Surgical, Maternal-Infantile and Adult Sciences, University Hospital of Modena, Via del Pozzo 71, 41124, Modena, Italy.

Emails: francesca.combi@unimore.it; francescacombi@msn.com

Keywords: BRCA-2 mutation, male breast cancer, psychological counseling, risk-reducing surgery

Male breast cancer accounts for about one percent of all breast cancer cases and is more common among individuals with a family history of breast cancer.

In particular, BRCA-2 mutation represents one of the most clearly established risk factors for male breast cancer. ${ }^{1,2}$ According to previous literature, $14 \%-16 \%$ of men with carcinoma of the breast are known to be BRCA-2 mutation carriers. ${ }^{3-5}$ On these bases, international guidelines recommend that all males diagnosed with breast cancer should undergo genetic testing. On the other hand, BRCA-1 mutation has a much lower incidence in male population.

In the present paper, we describe the uncommon case of a male bilateral risk-reducing mastectomy in a BRCA-2 male carrier.

A 37-year-old man with no relevant clinical history, highly educated and working in medical setting, with a family history of breast cancer, came to our Family Cancer Clinic to undergo genetic counseling. During the first evaluation, the family tree was drawn (Figure 1) and the family was judged worthy of BRCA genetic testing. Particularly, patient's father, diagnosed with breast cancer when 71 years old, performed genetic testing and resulted BRCA-2 carrier. We proposed to the patient an instrumental and clinical surveillance program for the risk of breast cancer, but also for the possible association with prostatic and gastro-intestinal tumors. The execution of a baseline mammary ultrasound did not reveal retro-areolar alterations nor the presence of nodules or gynecomastia. Since the patient was strongly affected by family experience, and by the progression of father's illness, he strongly requested a bilateral risk-reducing mastectomy. Although a guideline-based prevention program was planned with monthly self-examination, clinical check and breast ultrasound every 6 months, and tests for prostate cancer screening, the patient remained firm on the request for surgery. We proposed a psychological intervention, which he performed together with his wife. At first, his wife was skeptical about the surgical option, but finally she supported his choice. The couple was very collaborative and cohesive.

The patient showed a very proactive behavior, and he strongly motivated his choice underling the suffering of his father, the sense of responsibility upon his children, and the desire to avoid breast cancer. After this careful psychological counseling, the multi-disciplinary team concluded to proceed with surgery.

A bilateral simple mastectomy with nipple-areola complex removal was performed under general anesthesia. The postoperative course was regular. Final histology did not show the presence of any pathological tissue.

Clinical and instrumental follow-up is negative after 5 years. Nevertheless, no further follow-up will be available because the patient died by committing suicide.

Although male carriers of the BRCA-2 mutations have a markedly increased risk of breast cancer, the estimated lifetime risk in the general population of men is very low $(0.1 \%) .{ }^{1}$ Hence, this condition remains rare and no specific guideline suggests considering risk-reducing mastectomy as an option for males carrying the BRCA mutation.

Previous studies showed that, in cohorts of BRCA-2 women, breast cancer-specific survival resulted similar in patients that underwent surveillance and in patients who underwent risk-reduction surgery. ${ }^{6}$ Nonetheless, neither family history nor further risk factors were considered in the data recording. Beside the absence of overall and breast cancer-specific survival, the key role of tailored counseling is widespread. Factors like age at the time of diagnosis, 


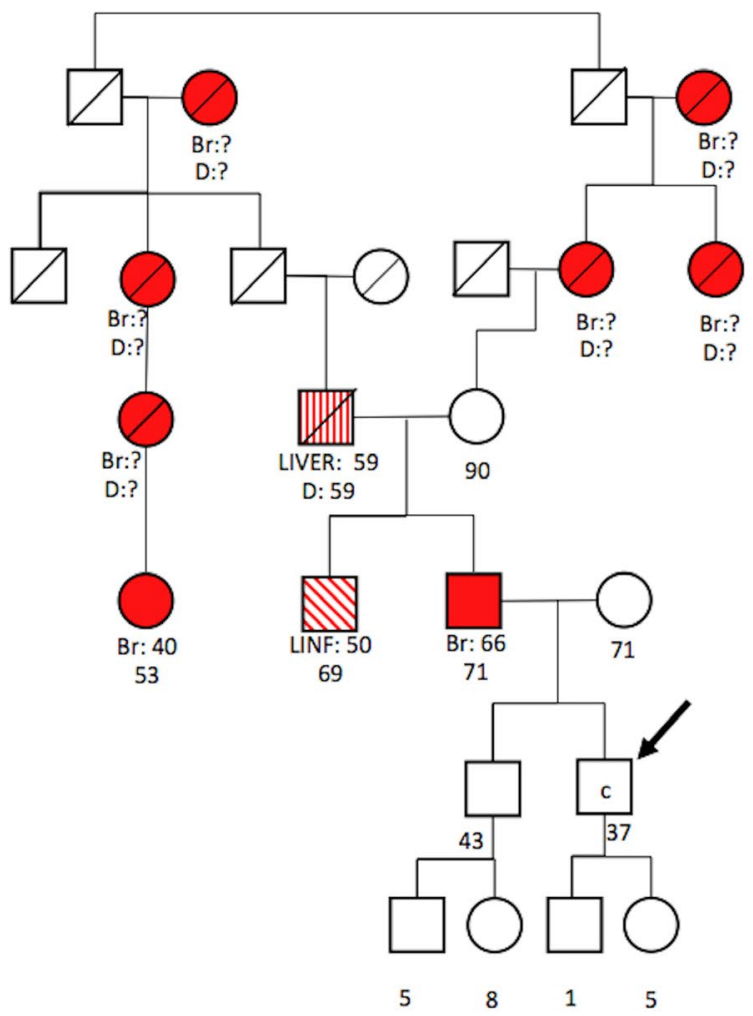

\begin{tabular}{|c|c|c|}
\hline & Male & Female \\
\hline \multicolumn{3}{|l|}{ Individual } \\
\hline \multicolumn{3}{|c|}{$\begin{array}{l}\text { Individual affected by } \\
\text { breast cancer }\end{array}$} \\
\hline \multicolumn{3}{|c|}{$\begin{array}{l}\text { Individual affected by } \\
\text { other cancer }\end{array}$} \\
\hline \multicolumn{3}{|l|}{ Deceased } \\
\hline \multicolumn{3}{|l|}{ Age } \\
\hline \multicolumn{3}{|l|}{ Age at death } \\
\hline $\begin{array}{l}\text { Age of onset of } \\
\text { cancer }\end{array}$ & $\begin{array}{c}\text { Br (breast): } \mathrm{n} \\
\text { Liver: } n \\
\text { Linf (Lymphoma): } n\end{array}$ & $\begin{array}{c}\text { Br (breast): } n \\
\text { Liver: } n \\
\text { Linf (Lymphoma): } n\end{array}$ \\
\hline Consultant & & \\
\hline
\end{tabular}

FIGURE 1 Family tree with legend

cancerophobia, low adherence to surveillance programs, or significant family history may sometimes influence the choice between surveillance and risk-reducing surgery.

In literature, male prophylactic mastectomy is described only in sporadic cases and always performed in men with BRCA mutation with a contralateral breast cancer diagnosis. ${ }^{7,8}$ Despite the absence of a survival benefit, ${ }^{9}$ the use of contralateral prophylactic mastectomy for men who received a diagnosis of unilateral breast cancer has substantially increased over time. ${ }^{8}$ The same trend is recognized in women population. ${ }^{10}$ This may suggest that patient's personal choice is becoming more and more important in genetic counseling.

Health care professionals have the role to educate patients on benefits, risks, and implications of surveillance programs versus risk-reducing strategies, and to flank the patient to reach shared decisions. This case may suggest that we need to tailor counseling and decision-making process for males carrying BRCA mutation and take into consideration risk-reduction surgery when wished and strongly motivated by the consultant or in the presence of multiple risk factors in addition to gene mutation.

In our experience, the involvement of family members in the counseling process is also greatly important.

\section{ORCID}

Francesca Combi iD https://orcid.org/0000-0001-7780-2851 Giovanni Tazzioli iD https://orcid.org/0000-0002-1102-7431

\section{REFERENCES}

1. Giordano SH. Breast cancer in men. $N$ Engl $J$ Med. 2018;378(24):2311-2320.

2. Ford D, Easton DF, Stratton M, et al. Genetic heterogeneity and penetrance analysis of the BRCA1 and BRCA2 genes in breast cancer families. The breast cancer linkage consortium. Am J Hum Genet. 1998;62(3):676-689.

3. Friedman LS, Gayther SA, Kurosaki T, et al. Mutation analysis of BRCA1 and BRCA2 in a male breast cancer population. Am J Hum Genet. 1997;60(2):313-319.

4. Ottini L, Masala G, D'Amico C, et al. BRCA1 and BRCA2 mutation status and tumor characteristics in male breast cancer: a population-based study in Italy. Cancer Res. 2003;63(2):342-347.

5. Ding YC, Steele L, Kuan C-J, Greilac S, Neuhausen SL. Mutations in BRCA2 and PALB2 in male breast cancer cases from the United States. Breast Cancer Res Treat. 2011;126(3):771-778.

6. Heemskerk-Gerritsen BAM, Jager A, Koppert LB, et al. Survival after bilateral risk-reducing mastectomy in healthy BRCA1 and BRCA2 mutation carriers. Breast Cancer Res Treat. 2019;177(3):723-733.

7. Guiahi M, Gabram SGA, Albain KS, Camacho P, Krishnamachari B, Rajan P. Clinical factors used to support prophylactic mastectomy for a male BRCA2 mutation carrier. Surgery. 2006;139(5):704-706.

8. Jemal A, Lin CC, DeSantis C, Sineshaw H, Freedman RA. Temporal trends in and factors associated with contralateral prophylactic mastectomy among US men with breast cancer. JAMA Surg. 2015;150(12):1192.

9. Meropol NJ, Schrag D, Smith TJ, et al. American Society of Clinical Oncology Guidance Statement: the cost of cancer care. JCO. 2009;27(23):3868-3874.

10. Kummerow KL, Du L, Penson DF, Shyr Y, Hooks MA. Nationwide trends in mastectomy for early-stage breast cancer. JAMA Surg. 2015;150(1):9. 